EPiC Series in Engineering
Volume 3, 2018, Pages 818-826
HIC 2018. 13th International
Conference on Hydroinformatics

\title{
Predicting Accurate Urban Flooding from Nuisance Flows to Major Disasters
}

\author{
Noemi Gonzalez-Ramirez, Ph.D. ${ }^{1}$, Fernando Nardi, Ph.D. ${ }^{2}$ and J. S \\ O'Brien, Ph.D ${ }^{1}$ \\ ${ }^{1}$ Riada Engineering, Inc., P.O. Box 104, Nutrioso, AZ 85932, United States \\ ${ }^{2}$ Università per Stranieri di Perugia, Piazza Fortebraccio, 4. 06123, Perugia Area, Italy. \\ noemi@flo-2d.com, fernando.nardi@unistrapg.it, jim@flo-2d.com
}

\begin{abstract}
Two-dimensional flood models are becoming increasing more accurate in simulating surface water flooding. Concurrently flood hazard maps have higher resolution to support flood mitigation planning. Most flood studies focus on large river flooding ( 100 -yr flood), but in urban areas, emergency access and evacuation routes are needed for frequent rainfall and flood events $(<10$-yr return periods). Urban flooding is more complex than river margin flooding and requires significantly more model detail to accurate access risk and hazard for frequent storms. Urban flooding is an event characterized by its frequent repetitive and systematic impact on population and urban infrastructure. Detailed urban flood inundation is now being performed with spatially and temporally variable rainfall and infiltration, channel and street flow, hydraulic structures, surface water storm drain exchange, building loss of storage and flow obstruction, building collapse, levee/wall overtopping and collapse, groundwater flow, sediment scour/deposition and mudflows. In residential neighborhoods, shallow flooding is controlled by streets, buildings, walls and storm drain facilities. Several flood model details and their impact on shallow flooding are discussed including spatially variable storm intensities on pervious and impervious surfaces, surface water exchange with limited storm drain system capacity, and building roof runoff. Several predictive strategies are highlighted to simulate flooding from nuisance flows to major disasters.
\end{abstract}

\section{Urban flooding interdependencies and area of inundation}

The urban environment is a complex system of sinks and sources, flow obstructions, and dynamic spatial and temporal interdependences that require linkage between model components to accurate predict flood hazards. To replicate a recent urban flood event (with NEXRAD rainfall data), a twodimensional flood routing model would need to simulate spatially and temporally variable rainfall, spatially and temporally variable infiltration (including impervious areas), street flow with storm drain 
inlets, building flow obstruction and loss of storage, building roof runoff, channel conveyance and channel/floodplain exchange, wall and levee overtopping and collapse, and possible hydraulic structure backwater. Each of these physical processes have to be simulated by model components that interact dynamically to predict water surface elevation and discharge. In addition, there may compounding influences on flow from groundwater recharge, sediment scour and erosion, sediment bulking, bridge and culvert blockage, storm drain inlet clogging, manhole popping, and mudflow cessation. All these physical processes can be interactively simulated with the FLO-2D model (O'Brien, 2012) in a single simulation. The FLO-2D model moves around blocks of fluid on a discretized grid system. Accurately predicting the flow interaction between urban features will reduce the flood hazard uncertainty.

\subsection{Spatially variable rainfall and infiltration on urban areas}

Virtually all rainfall/runoff models simulate rainfall events as spatially uniform rainfall with a temporal distribution. Furthermore, few two-dimensional flood modeling projects will have rainfall and infiltration on the overland progression of a river. This represents a major flaw in studies of flood frequency events because in most cases the 10-year storm (or smaller) predicted area of inundation may be a direct consequence of the rainfall runoff rather the overland river flooding. Often flooding of urban areas nestled against foothills is only consequence of local rainfall/runoff. In Figure 1, the area outside the red boundary is getting flooded by rainfall runoff because the watershed flood waves have not progressed through the red boundary.

Replicating historic rainfall events enables calibration of losses, identification of conveyance features such as channels and streets, identification of flow obstruction due to walls or embankments, and the simulation of surface water and the storm drain system. The project area in Figure 1 also has a complex mix of pervious and impervious areas. A discussion of the NEXRAD rainfall interpolation and the presentation of a flood animation reveals the importance of simulating street intersections, privacy wall collapse, and rainfall timing in concert with the watershed hydrograph to generate maximum flow depths and velocities. 


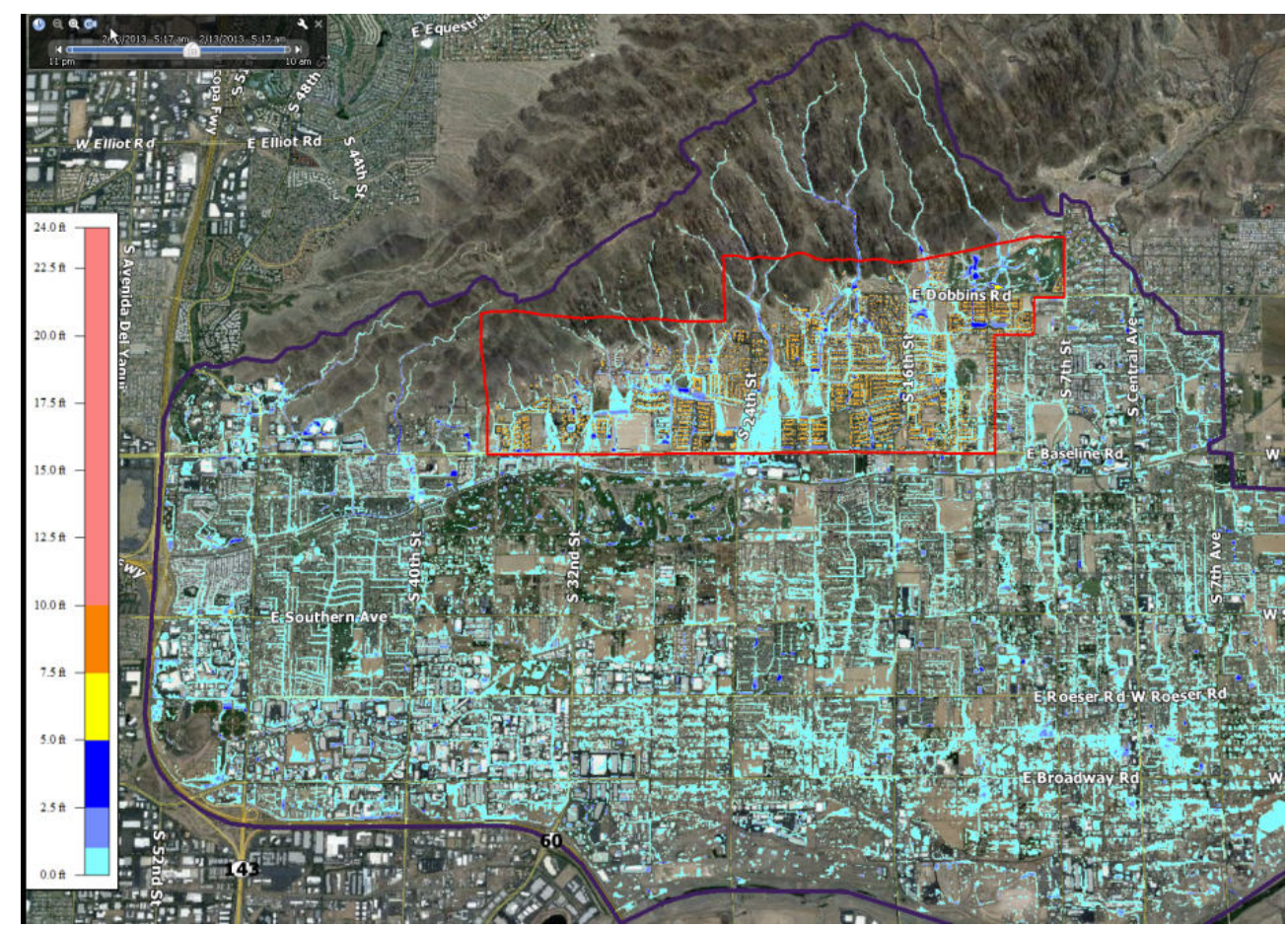

Figure 1: Urban Area Rainfall Flooding

\subsection{Surface water and the storm drain exchange}

A significant portion of the volume of a frequent storm $(<10$-year) may enter the storm drain system reducing the surface flooding. Both the inlet discharge and return flow must be integrated on a grid element and timestep basis for accurate surface flooding. The issue with EPA SWMM (Rossman, 2005) based models is that the storm drain system functions only as capacity limited with no knowledge of the surface water elevation in relationship to the storm drain pressure head. Without inlet control and a predicted surface water elevation, accurate storm drain simulation is impossible.

The FLO-2D model has been expanded with a storm drain component such that the surface water and closed conduit storm drain model systems are coupled with the computational engines running simultaneously (FLO-2D, 2018). A comparison of the grid element water surface elevation with the pressure head from the closed conduit system node in a given cell determines the direction of the flow exchanged between the two systems. The models are fully integrated on a computational timestep basis and the return flow that leaves the storm drain system flows away in the surface discretized model based on the interaction between urban features. 
The storm drain component has five inlet control types (weir or orifice flow whichever is smallest) that predict inflow or return flow based on the relationship between the surface water elevation, inlet geometry and pressure head. The inlet controlled discharge is then routed through the closed conduit system. When the storm drain system pressure is greater than the water surface elevation at inlet, manhole or outfall, the return flow to the surface water is computed. The storm drain system and data can be visualized and edited within the FLO-2D GUI (Figure 2 to Figure 5). The impact of simulating the storm drain system for a 10-yr rainfall event can be seen in Figure 7.

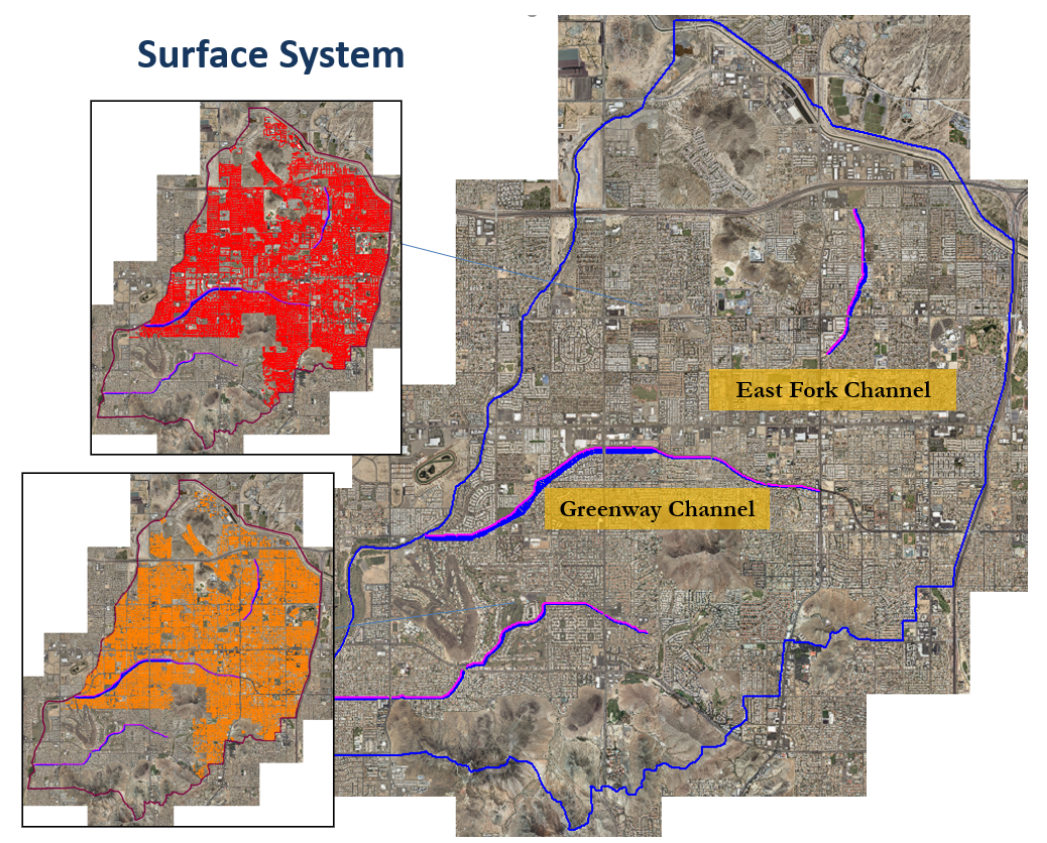

Figure 2: East Fork of Cave Creek Surface Features 


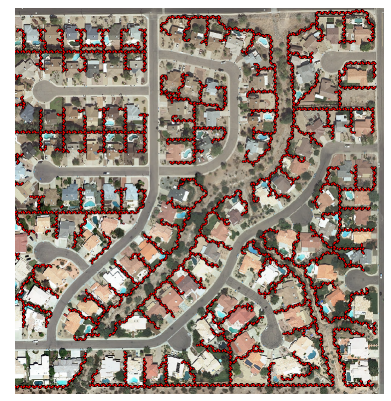

Figure 3: East Fork of Cave Creek Automated Wall Assignment

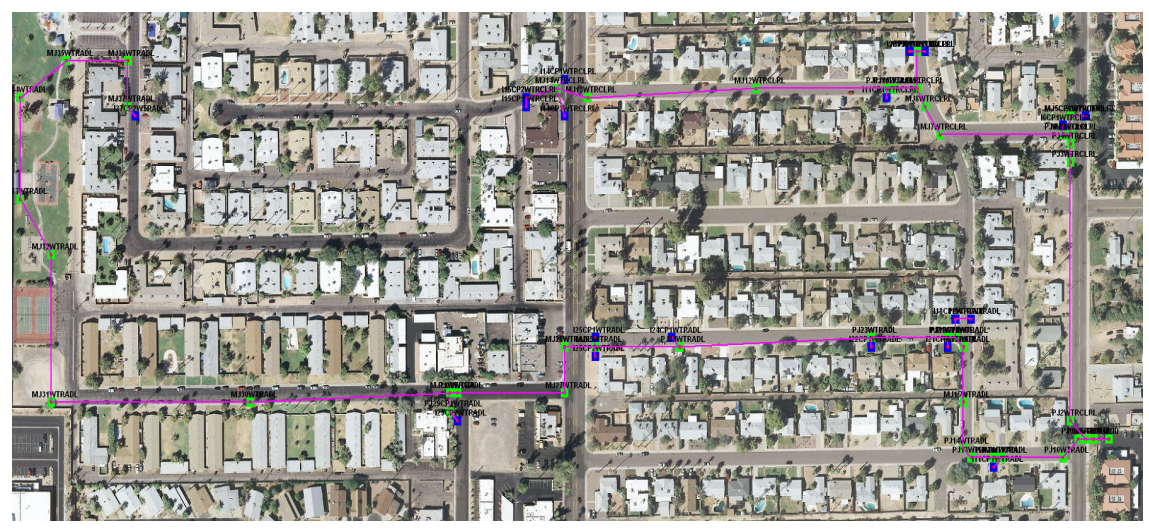

Figure 4: A Portion of Storm Drain System Displayed in the FLO-2D GDS

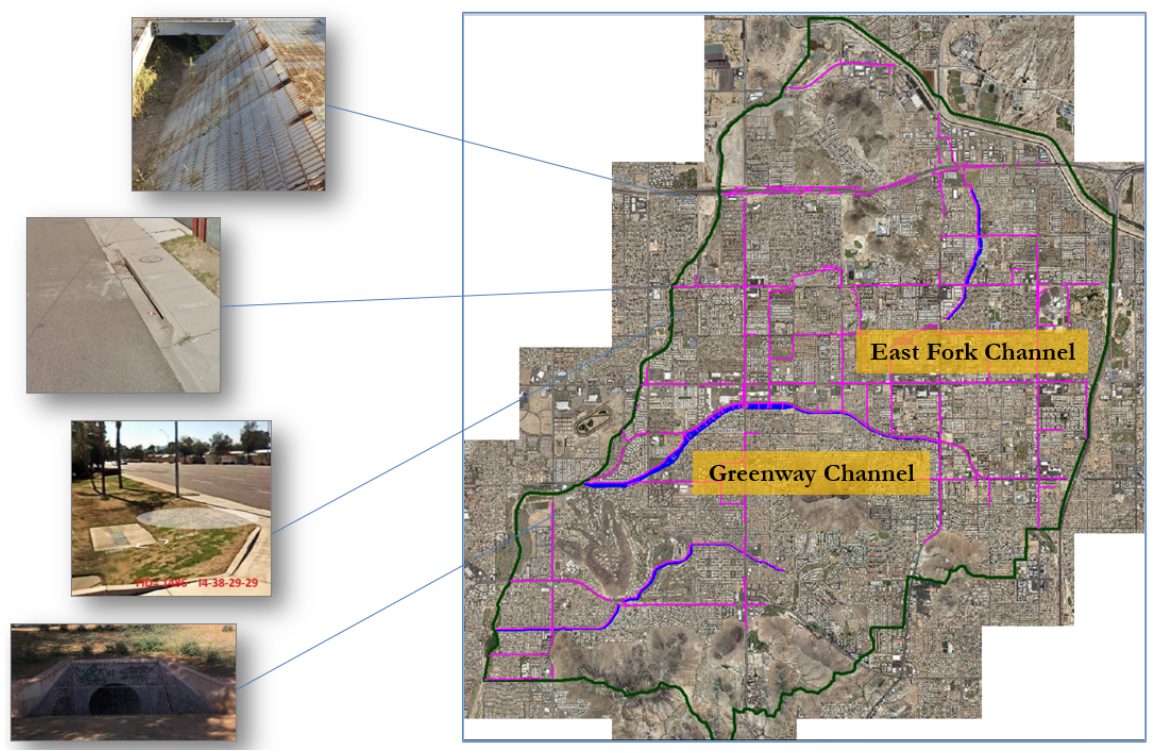

Figure 5: East Fork of Crave Creek Storm Drain System 
The FLO-2D storm drain model primary features are:

- Five inlet options, including manholes and unique inlet stage-discharge rating tables.

- Inlet/outfall return flow to the surface flooding based on pressure head vs water surface elevation for each computation timestep.

- Outfall return flow to channels and floodplain.

- Manhole cover popping with return flow to the surface water based on a surcharge depth (weight) with the cover staying off.

- Increased head on the inlets with gutter flow and street cross slope.

- Volume conservation reporting for both surface water and storm drain.

- The inlet orifice or weir discharge is subject to a clogging factor specified by the user.
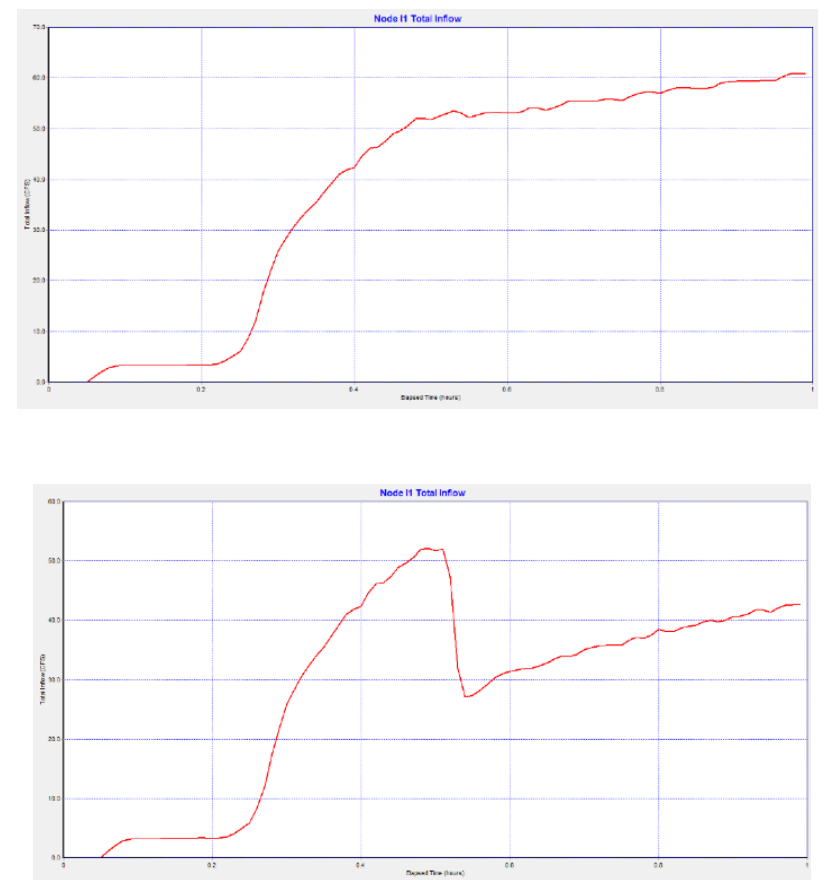

Figure 6: Type 2 Inlet Discharge versus Time using a Clogging Factor of $50 \%$ at time $0.5 \mathrm{hrs}$
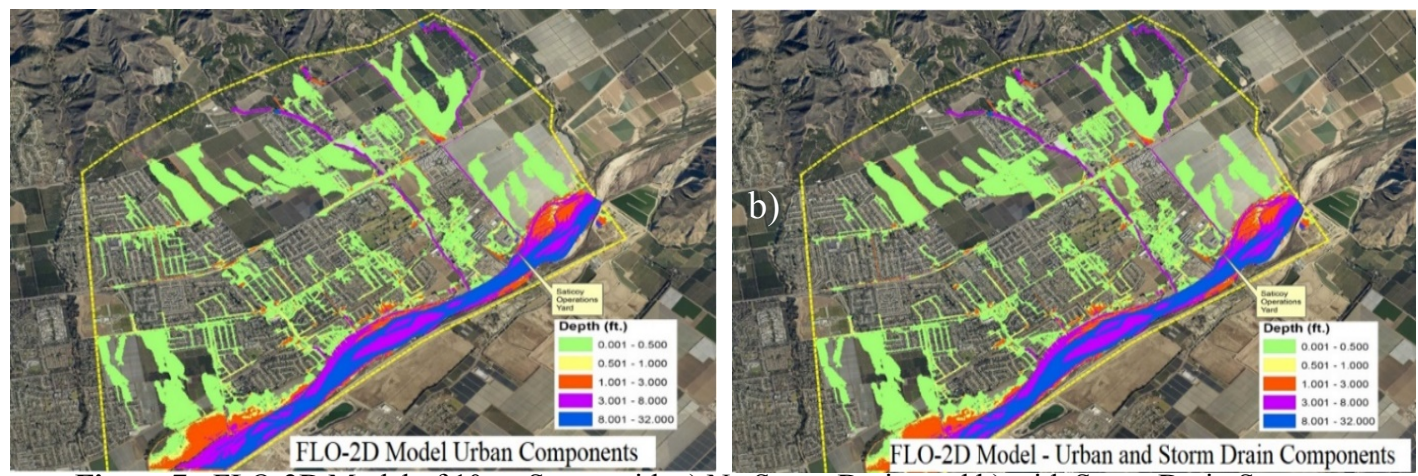

Figure 7: FLO-2D Model of 10-yr Storm with a) No Storm Drain, and b) with Storm Drain System 
The operational conditions of inlets affect the area of inundation for frequent flow events; however, the complex flow in streets and its control of the inlet discharge are often overlooked in urban flood models. Inlet clogging can be evaluated in sensitivity analysis to discern impact on the area of inundation for various flood frequency. Figure 6 shows the reduced discharge for a Type 2 inlet using a clogging factor of $50 \%$ at time $0.5 \mathrm{hrs}$.

\subsection{Street Gutter flow}

The street gutters are designed to convey shallow flow during storm runoff less than or equal to the design discharge without traffic interruption. Typical curb and gutter cross sections have a triangular shape created by the cross slope associated with the street or road crown. Gutter cross slopes can range from flat to $8 \%$ but for the FLO-2D street routing, the triangular shape is assumed to have a 2 percent straight cross slope (see Figure 8). The gutter flow will be exchanged with other upstream and downstream street gutter elements, the sidewalk, and other elements. The flow is shared between the gutter element and the contiguous floodplain elements using the floodplain flow depth and the gutter element sidewalk flow depth. The gutter data can be automatically created from shapefiles in the FLO2D model. The changes in the distribution of the flow comparing local depths with and without gutters are evident (see Figure 9).

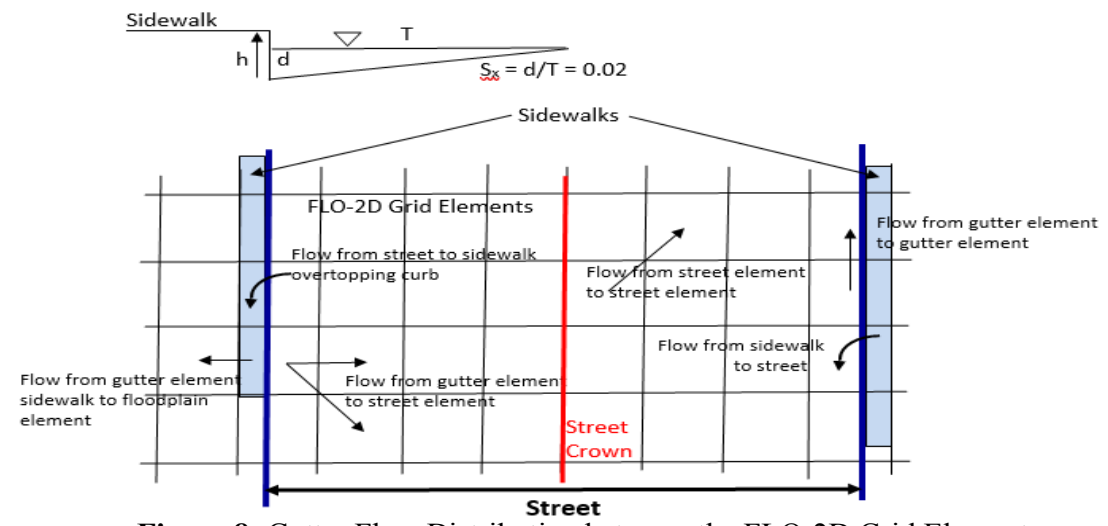

Figure 8: Gutter Flow Distribution between the FLO-2D Grid Elements
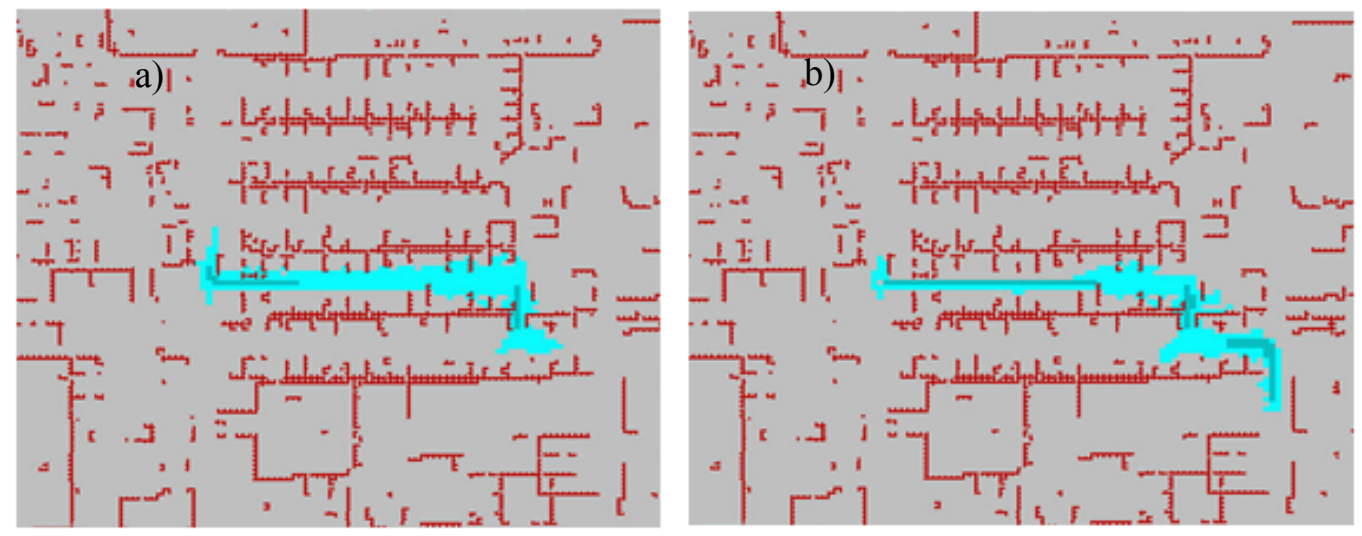

Figure 9: Flow Depths: a) Without Gutter; and b) With Gutter 


\subsection{Building roof rainfall runoff}

Rainfall runoff from building roofs can be a significant contribution to the surface flooding for all storm frequency events. Typically roof rainfall runoff is either ignored, assumed to enter the storm drain system or can't be simulated by flood models. Impervious building roofs represent a major portion of the land surface in cities like Phoenix, Arizona and the runoff to parking lots and streets is significant. In a $20-\mathrm{ft}(6.1 \mathrm{~m})$ grid system, the roof of a large mall may consist of over 500 grid elements (Figure 10). FLO-2D simulates the roof runoff based on roughness and roof element elevations. In the model, the building surface can be represented through the interpolation of building footprint shapefiles provided by the city or agency (Figure 11). For additional flood detail roof parapet walls and gutter downspouts can be simulated.

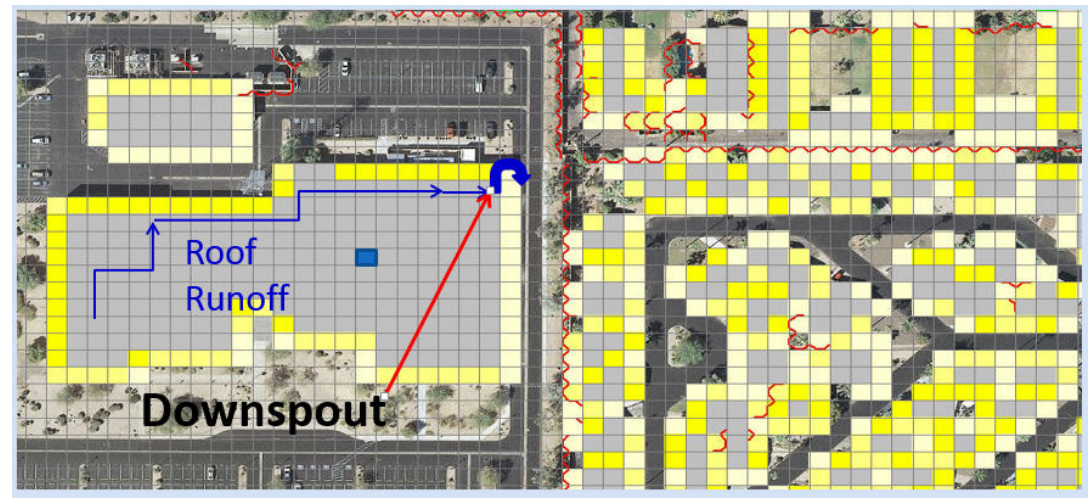

Figure 10: Building Roof Runoff to the Surface Flooding
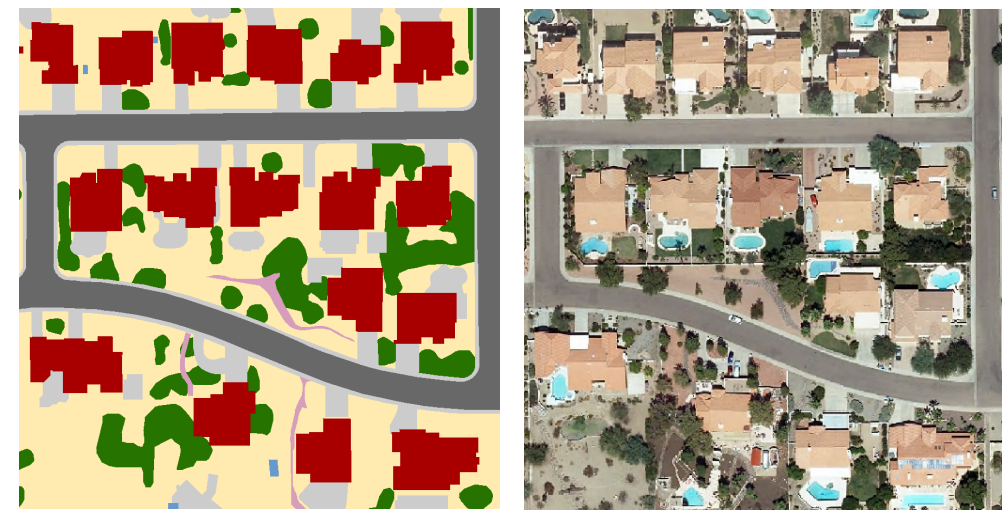

Figure 11: Surface Feature Assignment - Buildings

\subsection{Building collapse}

During a flood event or a mud/debris flow, it is possible that a building could collapse and be removed. In addition to building failure, the flooding could go through the previously occupied grid elements. To predict the collapse of the building during flooding vulnerability curves can be applied. Several approaches to predict building collapse have been evaluated (Bureau of Reclamation, 1988) (Pilotti, Melanesi, \& Ransi, 2016). After a comprehensive analysis, the following vulnerability curves (1-poor, 2-moderate, 3-good and 4-Clausen \& Clark (Clausen \& Clark, 1990) upper curve) in Figure 
12 have been implemented in the FLO-2D model. They include a global curve and spatial variable curve assignments.

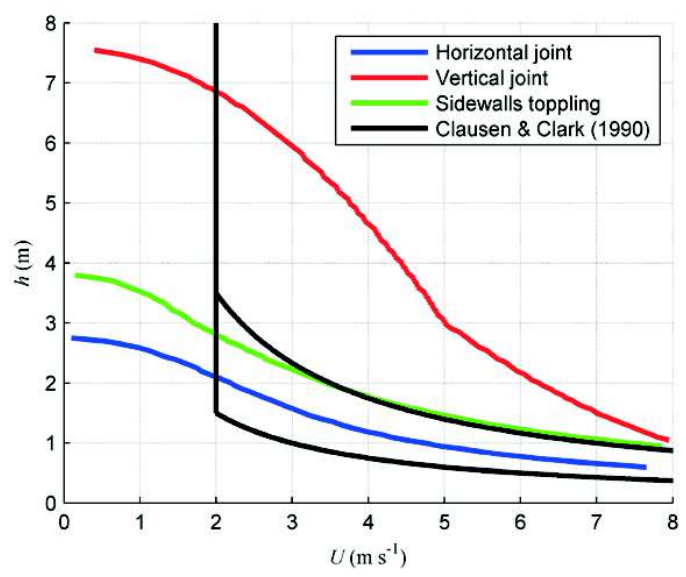

Figure 12: Vulnerability Curves for Building Subject to Collapse

\section{Conclusions}

Several novel urban flood modelling components are presented to enhance flood prediction accuracy and improve hazard map resolution. By combining components, a sensitivity analysis can be performed to determine the most important surface features that control the area of inundation from nuisance flows to major disasters. An urban drainage study can evaluate flood management strategies and low impact development techniques (LID) to design mitigation techniques. A master drainage plan conducted with a FLO-2D model may include:

- Assessment of the storm drain capacity;

- Existing response to floods events;

- Design of flood control and drainage system features;

- Analysis of urban surface features and their impact on the distributed volume;

- Design of evacuation plans, mitigation strategies and water protection programs. 